\title{
Risk factors for occupational accidents in agricultural enterprises in Japan
}

\author{
Goh ICHIHARA ${ }^{\mathbf{1}}$, Takehisa MATSUKAWA ${ }^{\mathbf{1}}$, \\ Fumihiko KITAMURA ${ }^{1}$ and Kazuhito YOKOYAMA ${ }^{1,2}$ *
}

\begin{abstract}
${ }^{1}$ Department of Epidemiology and Environmental Health, Juntendo University Faculty of Medicine, Japan
${ }^{2}$ Department of Epidemiology and Environmental Health, International University of Health and Welfare Graduate School of Public Health, Japan
\end{abstract}

Received December 27, 2017 and accepted December 7, 2018

Advanced Epub on J-STAGE February 13, 2019

\begin{abstract}
In Japan, the agricultural working environment has undergone significant changes from self-employment to enterprises and employees. As the structure of the agricultural industry changes, there has been a growing interest in occupational health and safety because agriculture is a hazardous industry. However, the public is not aware of the actual situation regarding occupational accidents in agricultural enterprises because most Japanese farmers are not necessarily required to report occupational accidents. The aim of this study is to explore the risk factors regarding occupational accidents for Japanese agricultural employees. We conducted a cross-sectional study among 1,606 employees at 101 agricultural enterprises in Japan. Information on occupational accidents, personal characteristics, and working conditions was collected by questionnaires. A total of 337 valid responses were obtained. Of these respondents, $104(30.9 \%)$ experienced occupational accidents. Multiple logistic regression analysis revealed that permanent employment (OR 3.67, 95\% CI, 1.84-7.33), pesticide use (OR 2.61, 95\% CI, 1.52-4.47), and long working hours (OR 1.76, 95\% CI, 1.15-2.68) were associated with the risk of occupational accidents. This study revealed the risk factors for occupational accidents for Japanese agricultural employees. It is suggested that workhour restrictions for permanent employees might contribute to reducing occupational accidents.
\end{abstract}

Key words: Occupational safety and health, Agricultural work, Japan, Agricultural enterprise, Agricultural employee

\section{Introduction}

In recent years, agriculture in Japan has undergone dramatic changes. Globalization and a lack of successors have resulted in a shift from primarily family-operated (self-employed) farms to agricultural businesses operated by corporations. Government growth strategies are also driving this development, and the further expansion of

*To whom correspondence should be addressed.

E-mail: kyokoya@juntendo.ac.jp

(C)2019 National Institute of Occupational Safety and Health business enterprises and an increase in the number of agricultural employees are expected in the future as a result of amendments to the Agricultural Land Act ${ }^{1-3)}$. These changes, however, have caused occupational health and safety problems characterized by occupational accidents ${ }^{4}$, suggesting that agriculture in Japan is becoming a dangerous industry with many occupational hazards.

The International Labor Organization (ILO) has proposed that agriculture is hazardous work ${ }^{5)}$, even in developed countries ${ }^{6-8)}$. Previous studies ${ }^{8,9)}$ suggest that most agricultural occupational accidents are injuries resulting from mistakes made while operating machinery. The first 
risk factor associated with mistakes in agricultural work is the physical nature of the work and that the resulting physical fatigue leads to a lack of concentration. Previous studies $^{5,10)}$ also report that in most countries, including developing countries, agricultural labor is often not conducted in accordance with national legislation such as labor laws or social insurance. This is because agriculture operations are mostly family-operated or small-scale enterprises, and overworking under such situations increases the risk of occupational accidents. It has been also pointed out that there exists a lack of understanding and training regarding hazards including pesticide exposure and their prevention on the part of both employers and employees regardless developed or developing countries, and that there are low levels of organization among agricultural workers ${ }^{5,11,12)}$. And these are leading to occupational accidents. In addition, child work is known as risk factor in developing countries ${ }^{13)}$, but that is hardly a problem in developed countries like Japan because child work is forbidden in principle.

In Japanese agriculture, overworking is common during the busy harvesting season ${ }^{14)}$. As mentioned above, almost all Japanese agriculture is carried out by self-employed workers. Therefore, most agriculture work is exempt from relevant regulations and labor laws such as the Japanese Occupational Safety and Health Act (J-OSHA, enacted in 1972). Depending on the Special Insurance System of the Industrial Accident Compensation Insurance Act, selfemployed in Japan can receive occupational accident insurance guarantee, but enrollment is optional and there are few people who enrolled. In the case of the self-employed, accidents during work time are their own responsibility. Thus, it has been difficult for the Japanese Government to regulate work environments such as overworking ${ }^{15,16)}$. As the structure of the agricultural industry changes, the number of agricultural employees has increased. Because of this change, the issue of occupational health is receiving greater attention among Japanese agricultural employees. However, Japanese government statistics show that it is difficult to ascertain the actual situation surrounding agricultural occupational accidents because of the number of self-employed farmers who are not required to report accidents under the J-OSHA. The Association of Japanese Agricultural Corporation reported $36 \%$ of agricultural corporations had experienced accidents in the past ${ }^{17)}$. While data on occupational accidents from the Industrial Accident Compensation Insurance System collected by the Japan Industrial Safety and Health Association are helpful, the data ${ }^{18)}$ does not purely reflect the actual situation facing agricultural employees because the system also accepts certain nonemployees who participate voluntarily. According to the data ${ }^{18)}$, a total of 1,260 workers experience occupational accidents in 2016, and calculated annual rate of 66 occupational accidents per 100,000 employees.

The data reveal that although fatal occupational accidents in all industries (only among employees) decreased from 5,000 cases in the 1970 s to less than 1,000 cases in $2015^{19)}$, the incidence rates per 100,000 workers of fatal accidents at work in 2006 was not so much different from other developed countries: 2.1 in Japan, 2.5 on average on the EU and 2.3 in the United States. The number of fatal accidents while farming (including nonemployees) remains high at approximately 400 cases per year ${ }^{20)}$. However, almost no statistical data (e.g., working hours) have been collected relating to occupational accidents among those agricultural workers because most agriculture work is exempt from the J-OSHA. Agricultural corporation were thought to tend not to report statistical data about occupational accidents. As mentioned above, for several decades almost all of the Japanese farmers are self-employed. JOSHA does not require such farmers to report the work accident. In addition, most of agricultural corporation (75\% in 2014) were non-stock company and they were considered to be extension of family-operated or selfemployment. Consequently, the actual situations and risk factors regarding occupational accidents while farming in Japan remains requires further investigation.

We suspect that agriculture in Japan is a hazardous industry involving many occupational accidents. The risk factors regarding occupational accidents are quantitative and qualitative overload, such as long working hours and machinery operation, pesticide exposure, and the absence of occupational safety systems. However, there have been few reports on occupational accidents while farming in agricultural enterprises in Japan ${ }^{21)}$. That study ${ }^{21)}$ conducted a questionnaire survey on 1,718 corporations joining Association of Japanese Agricultural Corporation in 2013. As a result, about $20 \%$ of corporations experienced occupational accidents in that year, and many of them were found to be permanent employees, but there was no analysis on the risk of occupational accidents. Nowadays, legal restrictions on occupational safety systems for nonpermanent employees, who are regarded as being particularly at risk, seek a reduction in occupational accidents ${ }^{22,23)}$. In contrast, the strengthening of legal restrictions regarding overworking employees has received considerable attention in Japan. The aim is to protect the safety and health of employees because permanent employees tend to have 
excessive workloads in both quantity and quality ${ }^{24,25)}$. However, agriculture is not subject to overtime work restrictions (with the exception of night work) because of its nature. This has resulted in a delay in implementing regulations, which can lead to occupational hazards. It is necessary to protect employee safety and health, even for agricultural employees, and it is necessary to investigate the actual situation and risk factors regarding occupational accidents. For the above reasons, the purpose of this study was to investigate occupational accidents and risk factors relating to agricultural employees in Japan.

\section{Subjects and Methods}

\section{Participants and study design}

We conducted a cross-sectional observational survey with questionnaires to examine the frequency of past occupational accidents and their risk factors. The present study targeted 1,606 agricultural employees working for 101 agricultural management enterprises throughout Japan. These enterprises participated in an earlier survey on occupational safety and health systems ${ }^{21)}$. The earlier survey targeted all 1,718 member enterprises of the Association of Japanese Agricultural Corporation (JAC), with 509 enterprises replying to the survey. Eventually, 101 enterprises agreed to distribute questionnaire forms among their employees. The flow of research was showed in Fig. 1. There are approximately 27,000 agricultural enterprises in Japan (September 2017), and JAC has only 1,900 members $^{26)}$. On the other hand, JAC is the only nationwide agricultural corporation network organization and public interest incorporated corporation in Japan. This study was carried out with the approval of the ethical committee of Juntendo University Faculty of Medicine (approval number 2014114).

\section{Procedure}

The questionnaire survey was conducted from December 2014 to January 2015. All participants were asked to provide basic personal information (e.g., age, sex, contract, job (e.g., production, processing, transport, sales)), working conditions (e.g., average working hours, number of rest days), and occupational accidents (e.g., experience of occupational accidents, details and seriousness of occupational accidents, multiple answer allowed) by using the category scale based on the "Special Survey Office of the Occupational Safety and Health Act (Ministry of Health,

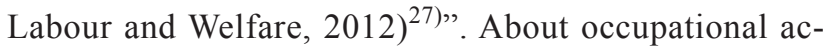
cidents, we asked about the contents of the occupational accident (machine injury, heat stroke, falling falls, etc.), how to deal with it (whether went to a hospital or not and whether used occupational accident insurance), and asked days of absent from work ( $0 \mathrm{~d}, 1$ to $3 \mathrm{~d}, 4 \mathrm{~d}$ or more). And we asked more detail about job type and working hours and rest days by adjusting the questionnaire, because it was thought that the result was very different depending on what type of occupation are the employees engaged in and whether it was a busy season. The questionnaire papers for employees were imprinted with their employer enterprise's number and distributed throughout the enterprises. All questionnaires were anonymous except for the enterprise identification number. Questionnaires were mailed back to us directly by employees without going through each enterprise. Employees were not obligated to return the questionnaires. Employee data were connected to their enterprise's occupational safety systems data collected in previous research ${ }^{21)}$ by the enterprise identification number. As a result, the enterprise's occupational safety systems data was connected to the employees' data.

\section{Statistical analysis}

In the statistical analysis, employees who did not provide valid responses in terms of their personal characteristics (age, sex, contract, job) and experience of occupational accidents (yes or no) were excluded. The primary outcome was the rate of experience of occupational accidents. Secondary outcomes were risk factors and associated odds ratios for occupational accidents. $\chi^{2}$ tests were conducted to compare the risk of occupational accidents based on personal characteristics, working conditions, and occupational safety systems between employees who had and had not experienced occupational accidents. Multiple logistic regression analysis was conducted with the stepwise method. Among the personal characteristics, working conditions, and occupational safety systems, we selected independent variables associated with occupational accidents and calculated odds ratios. Statistical analysis was performed using IBM SPSS ver. 24.0 for Windows (IBM Corp., Japan). The threshold for significance was $p<0.05$. Model performance was assessed using the HosmerLemeshow test for discrimination.

\section{Results}

From a total of 1,606 employees, responses were obtained from 390 individuals. Fifty-three employees did not fully complete the questionnaire and were excluded. Our analysis, therefore, included 337 participants (21.0\%). 


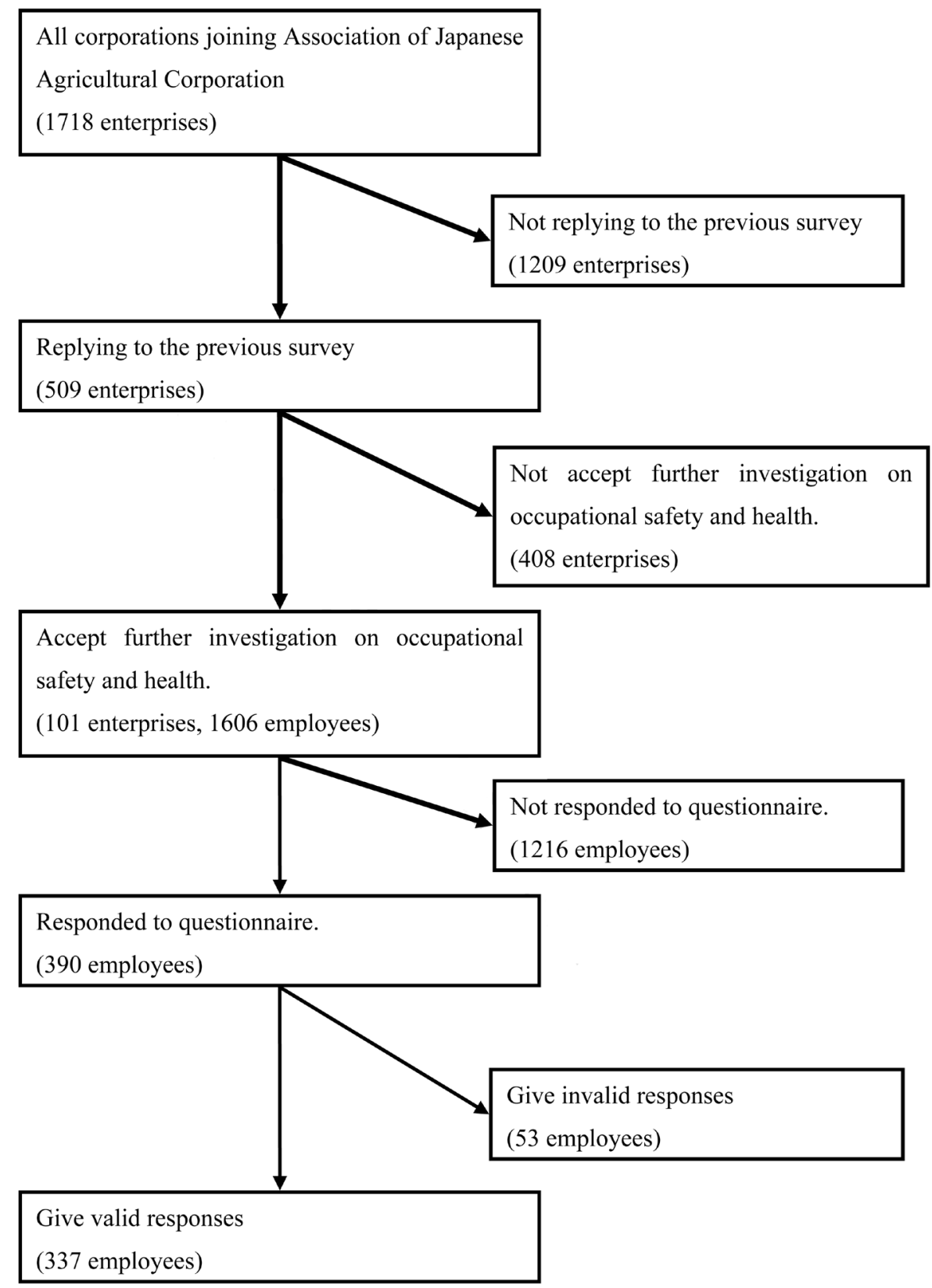

Fig. 1. Study flow diagram.

Table 1 shows overall sociodemographic characteristics and prevalence at occupational accident. The summary statistics of the experience of work accidents are presented in Table 2. From these 337 participants, 104 (30.9\%) had experienced occupational accidents while farming. Among these, 34 employees (10.1\%) experienced an injury that required an absence from work of $4 \mathrm{~d}$ or more. One person did not answer the days absent from work, it might because he did not remember the details of the accidents. There was no difference in the compensation that can be received from Industrial Accident Compensation Insurance between without lost workdays accident and absent up to $3 \mathrm{~d}$ accident. Such worker can receive medical treatment free of charge at medical facilities designated by Industrial Accident Compensation Insurance. However, it was thought that there were differences between without lost workdays accident and absent up to $3 \mathrm{~d}$ accident in the degree of the accidents. The annual rate of occupational accidents per 100,000 employees was calculated as 820 . The most common accidents were machinery injuries, 
Table 1. Difference in characteristics between workers with and without experience having occupational accidents

\begin{tabular}{lccc}
\hline \multirow{2}{*}{ Variables } & \multicolumn{2}{c}{ Experience having occupational accidents } & \multirow{2}{*}{$p$ value $^{\mathrm{a}}$} \\
\cline { 2 - 3 } & Yes $(\mathrm{n}=104)$ & No $(\mathrm{n}=233)$ & $<0.001$ \\
\cline { 1 - 2 } Sex & $73(42.0)$ & $101(58.0)$ & \\
$\quad$ Male & $31(19.0)$ & $132(81.0)$ & \\
$\quad$ Female & & & $<0.001$ \\
Age (yr) & $26(49.1)$ & $27(50.9)$ & \\
$\leq 29$ & $30(43.5)$ & $39(56.5)$ & \\
$30-39$ & $14(23.3)$ & $46(76.7)$ & \\
$40-49$ & $18(23.4)$ & $59(76.6)$ & \\
$50-59$ & $4(11.4)$ & $31(88.6)$ & \\
$60-64$ & $12(27.9)$ & $31(72.1)$ & \\
$\geq 65$ & & & \\
Employment contract & $88(39.8)$ & $133(60.2)$ & \\
Permanent & $16(13.8)$ & $100(86.2)$ & \\
$\quad$ Non-permanent & & & \\
Job & $80(38.8)$ & $126(61.2)$ & \\
Production & $24(18.3)$ & $107(81.7)$ & \\
Non-production & &
\end{tabular}

Data are presented as $\mathrm{n}(\%)$.

${ }^{\mathrm{a}} \chi^{2}$ test.

Table 2. Difference in days of absence from work between employees with and without compensation from Industrial Accident Compensation Insurance

\begin{tabular}{lcccr}
\hline \multirow{2}{*}{ Days absent from work } & \multicolumn{4}{c}{ Insurance compensation } \\
\cline { 2 - 5 } & Yes & No & No answer & \multicolumn{1}{c}{ Total } \\
\hline Not absent & $10(29.4)$ & $23(67.6)$ & $1(2.9)$ & $34(100.0)$ \\
Up to 3 d & $10(28.6)$ & $21(60.0)$ & $4(11.4)$ & $35(100.0)$ \\
4 d or more & $18(52.9)$ & $15(44.1)$ & $1(2.9)$ & $34(100.0)$ \\
No answer & $1(100.0)$ & $0(0.0)$ & $0(0.0)$ & $1(100.0)$ \\
Total & $39(37.5)$ & $59(56.7)$ & $6(5.8)$ & $104(100.0)$ \\
\hline
\end{tabular}

Data are presented as $\mathrm{n}(\%)$.

41 people (12.2\%). The second was back pain 36 people $(10.7 \%)$, the third was fallen from the machines, 26 people (7.7\%). The accidents that required $4 \mathrm{~d}$ of absence or more were also the same order. The number of those people were 15 in machinery injuries, 10 in back pain and 8 in fallen from the machines.

Table 3 shows a comparison of the descriptive statistics of personal characteristics, and the work-related variables between employees who had and had not experienced occupational accidents. Employees who had experienced occupational accidents were more likely to work as permanent employees, engage in production jobs, have long working hours and fewer rest days, use pesticides, and be male.

The associations between working conditions and occupational accidents are presented in Table 4. The multivariate logistic regression analysis revealed that permanent employment (OR, 3.668; 95\% CI, 1.835-7.330), long working hours (OR, 1.757; 95\% CI, 1.153-2.681), and pesticide use (OR, 2.608; 95\% CI, 1.521-4.471) significantly increased the risk of occupational accidents. In The Hosmer-Lemeshow test of the study model, the rate of discrimination between the predicted and actual values was $72.6 \%$, with the $p$-value of 0.432 , indicating a well fitted model.

In stratified analysis by employment status, in permanent employee, the odds ratio for the occupational accident was elevated for pesticide use $(\mathrm{OR}=2.93,95 \% \mathrm{CI}$ 1.64-5.21). On the other hand, in non-permanent employees, there was no significant relationship between the risk 
Table 3. Difference in work-related variables between workers with and without experience having occupational accidents

\begin{tabular}{|c|c|c|c|}
\hline \multirow{2}{*}{ Variables } & \multicolumn{2}{|c|}{ Experience having occupational accidents } & \multirow{2}{*}{$p$ value $^{\mathrm{a}}$} \\
\hline & Yes $(n=104)$ & No $(\mathrm{n}=233)$ & \\
\hline Working hours per day & & & 0.005 \\
\hline$\leq 5.99 \mathrm{~h}$ & $6(15.0)$ & $34(85.0)$ & \\
\hline $6-7.99 \mathrm{~h}$ & $59(29.1)$ & $144(70.9)$ & \\
\hline $8-9.99 \mathrm{~h}$ & $33(38.4)$ & $53(61.6)$ & \\
\hline$\geq 10 \mathrm{~h}$ & $5(71.4)$ & $2(28.6)$ & \\
\hline Unclear & $1(100.0)$ & $0(0.0)$ & \\
\hline Overtime working hours per month & & & $<0.001$ \\
\hline$\leq 29 \mathrm{~h}$ & $33(19.2)$ & $139(80.8)$ & \\
\hline $30-44 \mathrm{~h}$ & $29(49.2)$ & $30(50.8)$ & \\
\hline $45-79 \mathrm{~h}$ & $23(45.1)$ & $28(54.9)$ & \\
\hline$\geq 80 \mathrm{~h}$ & $13(38.2)$ & $21(61.8)$ & \\
\hline Unclear & $6(28.6)$ & $15(71.4)$ & \\
\hline Rest days per month in the busy season & & & $<0.001$ \\
\hline$\leq 4 \mathrm{~d}$ & $65(43.6)$ & $84(56.4)$ & \\
\hline $5-7 \mathrm{~d}$ & $27(22.5)$ & $93(77.5)$ & \\
\hline$\geq 8 \mathrm{~d}$ & $11(18.6)$ & $48(81.4)$ & \\
\hline Unclear & $1(11.1)$ & $8(88.9)$ & \\
\hline Average sleep hours per day & & & 0.127 \\
\hline$\leq 4.99 \mathrm{~h}$ & $4(28.6)$ & 10 (71.4) & \\
\hline $5-5.99 \mathrm{~h}$ & $28(35.4)$ & $51(64.6)$ & \\
\hline $6-6.99 \mathrm{~h}$ & $49(35.5)$ & $89(64.5)$ & \\
\hline $7-7.99 \mathrm{~h}$ & $19(24.1)$ & $60(75.9)$ & \\
\hline$\geq 8 \mathrm{~h}$ & $4(14.8)$ & $23(85.2)$ & \\
\hline Pesticide use & & & $<0.001$ \\
\hline Yes & $58(46.0)$ & $68(54.0)$ & \\
\hline No & $39(20.1)$ & $155(79.9)$ & \\
\hline Unclear & $7(41.2)$ & $10(58.8)$ & \\
\hline Annual general checkup & & & 0.766 \\
\hline Done & $82(30.5)$ & $187(69.5)$ & \\
\hline Not done & $22(32.4)$ & $46(67.6)$ & \\
\hline Safety training & & & 0.24 \\
\hline Done & $26(26.5)$ & $72(73.5)$ & \\
\hline Not done & $70(33.2)$ & $141(66.8)$ & \\
\hline Unclear & $8(28.6)$ & $20(71.4)$ & \\
\hline Safety and health committee & & & 0.541 \\
\hline Exists & $24(34.3)$ & $46(65.7)$ & \\
\hline Does not exist & $78(30.5)$ & $178(69.5)$ & \\
\hline Unclear & $2(18.2)$ & $9(81.8)$ & \\
\hline Size of worksite & & & 0.62 \\
\hline$\leq 9$ employees & $42(30.0)$ & $98(70.0)$ & \\
\hline 10-49 employees & $40(29.4)$ & $96(70.6)$ & \\
\hline$\geq 50$ employees & $22(36.1)$ & $39(63.9)$ & \\
\hline Safety and health members & & & 0.38 \\
\hline Exist & $45(33.6)$ & $89(66.4)$ & \\
\hline Do not exist & $59(29.1)$ & $144(70.9)$ & \\
\hline
\end{tabular}

Data are presented as $\mathrm{n}(\%)$.

Categorized as unclear in this table were excluded from $\chi^{2}$ test. ${ }^{\mathrm{a}} \chi^{2}$ test. 
Table 4. Effects of occupational factors on occupational accidents: stepwise logistic regression analysis ${ }^{\mathrm{a}}$

\begin{tabular}{lc}
\hline & Odds ratio (95\% confidence intervals) \\
\hline Employment contract & 1 \\
$\quad$ Non-permanent & $3.67(1.84-7.33)$ \\
Permanent & \\
Working hours per day & 1 \\
$<8 \mathrm{~h}$ & $1.76(1.15-2.68)$ \\
$\geq 8 \mathrm{~h}$ & 1 \\
Pesticide use & \\
No & $2.61(1.52-4.47)$ \\
Yes
\end{tabular}

andependent variables examined were sex, age, employment contract, pesticide use, hours worked per day, overtime hours per month, average hours of sleep, annual general checkup, and safety training.

of occupational accidents and the risk factors identified above.

\section{Discussion}

This study identified the associations between working conditions and occupational accidents in agricultural employees in Japan. We looked at the annual rate of occupational accidents per 100,000 employees (accidents that required an absence from work of $4 \mathrm{~d}$ or more) to compare the rate of occupational accidents with other industries. Because the Japanese government reports the rate of occupational accidents in three different ways (by severity, frequency, and the annual rate of occupational accidents), severity and frequency were evaluated based on data from workplaces that had 100 or more employees. According to a previous report from Japan, agricultural enterprises are not likely to hire that many employees ${ }^{10)}$. This result was the same in our study: the largest enterprise hired 80 employees. Other countries for example in the EU, agriculture suffers from the declining production population as in Japan, so agriculture ranks as a small business in other developed countries. Therefore, it was evaluated the rate of occupational accidents looking at the annual rate per 100,000 employees because it is based on all workplaces, including those that hire less than 100 employees.

In our study, the annual rate of occupational accidents per 100,000 employees was 820 , which is much higher than the reported rate, 220, for all other industries in Ja$\mathrm{pan}^{28)}$. Even if calculated only using those cases reported to the Labor Standards Inspection Office (18 employees), the rate is 450 , which is close to twice as high as that of all other industries. Therefore, we conclude that here in
Japan, as in other developed countries, agriculture is a still dangerous industry experiencing many occupational accidents.

Furthermore, it was suspected that the risk factors for occupational accidents while farming involved quantitative and qualitative overload such as long working hours, chemical substance exposure, and inadequate occupational safety systems from previous studies ${ }^{5,9}$. In this study, it was showed that permanent employment, long working hours, and the use of agricultural pesticides were risk factors for occupational accidents.

Previous studies have revealed that nonpermanent employment is a risk factor for the occurrence of occupational accidents ${ }^{23)}$. However, those studies were conducted outside Japan. There are differences in the responsibilities and roles of nonpermanent employees across countries, making simple comparisons challenging. In Japanese industries, there is a tendency to assign tasks involving more responsibility (in terms of quality) and harder work (in terms of quantity) to permanent employees rather than nonpermanent employees ${ }^{25}$. Permanent employees are expected to work for longer periods than nonpermanent employees, so they are more likely to get a chance of skill training: for example, get a machine license, than nonpermanent employees. Therefore, dangerous work such as machine operation might have been increased. We had not asked about whether employees were skills such as operating machinery, but it was supposed these trends do not change. Therefore, permanent employees may take on more dangerous tasks, such as operating machinery, in comparison to nonpermanent employees. Another possible explanation for why permanent employees tend to experience occupational accidents is that employees in unstable contracts may hesitate to report occupational accidents to increase their chances of obtaining permanent contracts and greater job security. However, in our study, we collected questionnaires directly from employees, so that their employers did not know their answers. Therefore, it was supposed that such hesitation to report accidents would not have occurred in our study.

When employees work long hours (more than $8 \mathrm{~h}$ per day), they are more fatigued and their ability to concentrate declines, therefore Labor Standards Act prohibit more than $8 \mathrm{~h}$ work in Japan. As the ILO ${ }^{5)}$ and other studies reported $^{9,29,30)}$, a lack of attention increases the risk of occupational accidents such as making mistake when operating machinery. Therefore, it was supposed that long working hours could easily lead to occupational accidents $5,9,29,30$.

The survey results showed that employees who respond- 
ed that they used pesticides during work had a significantly higher risk of occupational accident. However, only one person answered that they suffered an occupational accident relating to pesticide poisoning. Hence, that result might be due to confounding variables, such as agricultural employment experience ${ }^{31)}$, rather than pesticide use itself. With respect to work experience, farmworkers who handle pesticide possess assigned to other skilled work than farmworkers without such experience.

There were no statistically significant differences in the incidence of occupational accidents according to whether enterprises had established occupational safety systems (such as safety and health committees, and safety training). The authorities have made these systems mandatory and shown to reduce occupational accidents and significant reduction has also been shown in the past study ${ }^{22}$. It may be that occupational safety and health programs are ineffective because authorities are not monitoring these situations. In the current study, we only asked whether such systems had been implemented, and we did not evaluate their content. Therefore, it was considered that the occupational safety systems did not function properly, despite being in place. The enterprises that agreed to participate in this research were thought to be more likely to be taken as indicating that they were properly aware of safety and health requirements at work and their legal obligations, because we targeted employees of the enterprises that agree with further investigation on occupational safety and health. Nevertheless, there were just 39 reported occupational accidents from 104 accidents (37.5\%). Even regarding serious accidents (that required an absence from work of $4 \mathrm{~d}$ or more), only half were reported. All enterprises are required to join the Industrial Accident Compensation Insurance, and must report occupational accidents as they occur. Enterprises may fail to report accidents because they have an insufficient understanding of safety and poor safety operations, or they are afraid of monitoring by the authorities ${ }^{32)}$. To ensure the effectiveness of occupational safety systems (e.g., effective safety training), industry collaboration (e.g., sharing effective information on safety) is necessary. However, because the government is not monitoring or regulating the situation, industry awareness toward the reduction of occupational accidents is very low. Thus, it seems likely that the improvement of occupational safety systems did not lead to a reduction of occupational accidents in this study.

\section{Limitation}

This research has several limitations. Employees who experienced occupational accidents were more willing to respond to the survey than those who has not, and this may have caused selection bias because there is no incentive or compulsion for employees. It was suspected that employees who responded to the questionnaire were more likely to have dissatisfaction with current occupational safety than employees who did not respond. And we did not ask whether employees are Japanese or foreigner. The proportion of foreign workers in Japan, including technical interns, was less than $10 \%$ at the agricultural corporation in $2014^{33)}$. In addition, if the foreign employee could reply to our Japanese questionnaire, the employee can deem having job skills of a sufficiently high level same as Japanese employees. Furthermore, this study was unable to examine cases of fatal accidents. In addition, the definition of occupational accidents used here is different from that accredited by the Industrial Accident Compensation Insurance. This is because we used data concerning what employees believed constitutes an occupational accident. Finally, it may be that the participating agricultural enterprises may have caused selection bias. Because there are approximately 27,000 agricultural enterprises in Japan, but JAC has only 1,900 members $^{26)}$ and replied only 101 enterprises in our study. Therefore, such enterprises may have interested in occupational health and safety, and they may have been more likely to provide exemplary responses.

Nevertheless, this study makes a number of valuable contributions that should be mentioned. Agriculture alone has produced more than one third of fatal accidents in all industries, which suggests that agricultural occupational accidents must be mitigated. This requires immediate action. To protect the safety and health of employees, it is important to gather and analyze work-related accidents. For this purpose, we supposed that it was not as important whether such cases were accredited by the Industrial Accident Compensation Insurance. Because the occupational accidents that we should consider reducing are the accidents that are widely regarded as work related injuries or illnesses. It does not matter whether the accidents are accredited by the Industrial Accident Compensation Insurance or not.

In conclusion, we found that being a permanent employee, working long hours, and using agricultural pesticides were risk factors associated with occupational accidents for Japanese agricultural employees. The reduction of quality and quantity overload (such as long working hours) might contribute to reducing agricultural occupational accidents. In addition, it may be necessary 
for the authorities to establish, monitor and provide advice on occupational safety systems.

\section{Conflict of Interest}

The authors declare that they have no conflict of interest.

\section{Acknowledgements}

This work was supported by a KAKENHI Grant for Challenging Exploratory Research (Grant number 25670324) from the Japan Society for the Promotion of Science, Japan. We thank Katie Stallard, LLB, from Edanz Group (www.edanzediting.com/ac) for editing a draft of this manuscript.

\section{References}

1) Matsuo Y (2013) Examining current Japanese agricultural policies. Senshu Univ Inst Humanit Mon Bull 265, 33-49.

2) Hori M, Kawashima E, Yamazaki T (2010) Application of cloud computing to agriculture and prospects in other fields. Fujitsu Sci Tech J 46, 446-54.

3) Japan Ministry of Agriculture, Forestry and Fisheries (2012) Heisei 24th edition Food, Agriculture, Rural White Paper, 140-51, Agriculture and Forest Statistics Association, Tokyo (in Japanese).

4) Matsukawa T, Yokoyama K, Itoh H (2015) Ocular irritation from product of pesticide degradation among workers in a seed warehouse. Ind Health 53, 95-9. [Medline] [CrossRef]

5) International Labour Organization Agriculture: a hazardous work. http://www.ilo.org/safework/areasofwork/hazardouswork/WCMS_356550/lang-en /index.htm Accessed July 23, 2018.

6) Myers JR, Hard DL (1995) Work-related fatalities in the agricultural production and services sectors, 1980-1989. Am J Ind Med 27, 51-63. [Medline] [CrossRef]

7) Lee K, Lim HS (2008) Work-related injuries and diseases of farmers in Korea. Ind Health 46, 424-34. [Medline] [CrossRef]

8) Franklin RC, Mitchell RJ, Driscoll TR, Fragar LJ (2001) Agricultural work-related fatalities in Australia, 1989-1992. J Agric Saf Health 7, 213-27. [Medline]

9) Svendsen K, Aas O, Hilt B (2014) Nonfatal occupational injuries in Norwegian farmers. Saf Health Work 5, 147-51. [Medline] [CrossRef]

10) National Chamber of Agriculture Questionnaire survey on the actual condition of employment in agricultural corporations. https://www.nca.or.jp/Be-farmer/statistics/pdf/ Y5Gn0LliRSfVioB2cM0N201206271419.pdf (in Japanese) Accessed July 23, 2018.

11) Nag PK, Nag A (2004) Drudgery, accidents and injuries in Indian agriculture. Ind Health 42, 149-62. [Medline]
[CrossRef]

12) Kimura K, Yokoyama K, Sato H, Nordin RB, Naing L, Kimura S, Okabe S, Maeno T, Kobayashi Y, Kitamura F, Araki S (2005) Effects of pesticides on the peripheral and central nervous system in tobacco farmers in Malaysia: studies on peripheral nerve conduction, brain-evoked potentials and computerized posturography. Ind Health 43, 285-94. [Medline] [CrossRef]

13) Gamlin J, Hesketh $T$ (2007) Child work in agriculture: acute and chronic health hazards. Child Youth Environ 17, $1-23$.

14) Tachi S, Niisato $Y$ (2000) Time budget of tulip bulb farmers in Japan and Holland in busy season. Jpn J Farm Work Res 35, 211-21 (in Japanese). [CrossRef]

15) Matsukawa $T$, Yokoyama K (2014) Agricultural workers in Japan. Juntendo Med J 60, 425-31. [CrossRef]

16) Matsukawa T, Yokoyama $K$ (2013) Occupational health and safety of pesticide handling workers. Occup Health J 36, 78-81 (in Japanese).

17) Association of Japanese Agricultural Corporation Agricultural corporation White Paper, 17, Association of Japanese Agricultural Corporation, Tokyo (in Japanese).

18) Japan Industrial Safety and Health Association Occupational accident analysis data http://www.jisha.or.jp/ info/bunsekidata/pdf/6011.pdf (in Japanese) Accessed July 23, 2018.

19) Japan Ministry of Health, Labour and Welfare. Annual report for Industrial Accident Compensation Insurance. http://www.mhlw.go.jp/toukei/itiran/roudou/hoken-jigyo/ gaiyou/dl/h27_nenpou_all.pdf (in Japanese) Accessed July 23, 2018.

20) Japan Ministry of Agriculture Forestry and Fisheries. Outline of farm work death accident occurred in Heisei 27th. http://www.maff.go.jp/j/press/seisan/sizai/attach/ pdf/170206-1.pdf (in Japanese) Accessed July 23, 2018.

21) Matsukawa T, Yokoyama K (2015) Research on pesticide problems as occupational safety and health. Occup Health J 38, 70-5 (in Japanese).

22) Yoon SJ, Lin HK, Chen G, Yi S, Choi J, Rui Z (2013) Effect of occupational health and safety management system on work-related accident rate and differences of occupational health and safety management system awareness between managers in South Korea's construction industry. Saf Health Work 4, 201-9. [Medline] [CrossRef]

23) Im HJ, Oh DG, Ju YS, Kwon YJ, Jang TW, Yim J (2012) The association between nonstandard work and occupational injury in Korea. Am J Ind Med 55, 876-83. [Medline] [CrossRef]

24) Yamauchi $T$, Yoshikawa $T$, Takamoto M, Sasaki $T$, Matsumoto S, Kayashima K, Takeshima T, Takahashi M (2017) Overwork-related disorders in Japan: recent trends and development of a national policy to promote preventive measures. Ind Health 55, 293-302. [Medline] [CrossRef]

25) Koji T, Haruhiko H, Yasutaka F, Seiga L, Tomohiko M, Shingou I (2014) Research on work and life of irregular 
workers in late middle age., 62-8, The Japan Institute for Labour Policy and Training, Tokyo (in Japanese).

26) Association of Japanese Agricultural Corporation About us. http://hojin.or.jp/common/ (in Japanese) Accessed July 23, 2018.

27) Japan Ministry of Health, Labour and Welfare. Occupational Safety and Health Survey Questionnaire. http://www.mhlw. go.jp/toukei/chousahyo/h24_kenkoujyoukyouchousa_2.pdf (in Japanese) Accessed July 23, 2018.

28) Japan Ministry of Health, Labour and Welfare. Trends in the thousand employees per year rate by industries. http:// anzeninfo.mhlw.go.jp/user/anzen/tok/h28_senninritsu2.xlsx (in Japanese) Accessed July 23, 2018.

29) Chae H, Min K, Youn K, Park J, Kim K, Kim H, Lee K (2014) Estimated rate of agricultural injury: the Korean Farmers' Occupational Disease and Injury Survey. Ann Occup Environ Med 26, 8. [Medline] [CrossRef]
30) Dong XS, Wang X, Largay JA (2015) Occupational and non-occupational factors associated with work-related injuries among construction workers in the USA. Int J Occup Environ Health 21, 142-50. [Medline] [CrossRef]

31) Kandel WA, Donato KM (2009) Does unauthorized status reduce exposure to pesticides? Evidence from the national agricultural workers survey. Work Occup 36, 367-99. [CrossRef]

32) Japan Ministry of Health, Labour and Welfare. Hiding occupational accidents is a crime. http://hyogoroudoukyoku.jsite.mhlw.go.jp/library/hyogo-roudoukyoku/ seido/roudou_jyouken/rosaikakushi.pdf (in Japanese) Accessed July 23, 2018.

33) Horiguchi K. Logic of farm labor procurement and labor market opening (KAKENHI Research result report). Waseda University, Tokyo (in Japanese). 